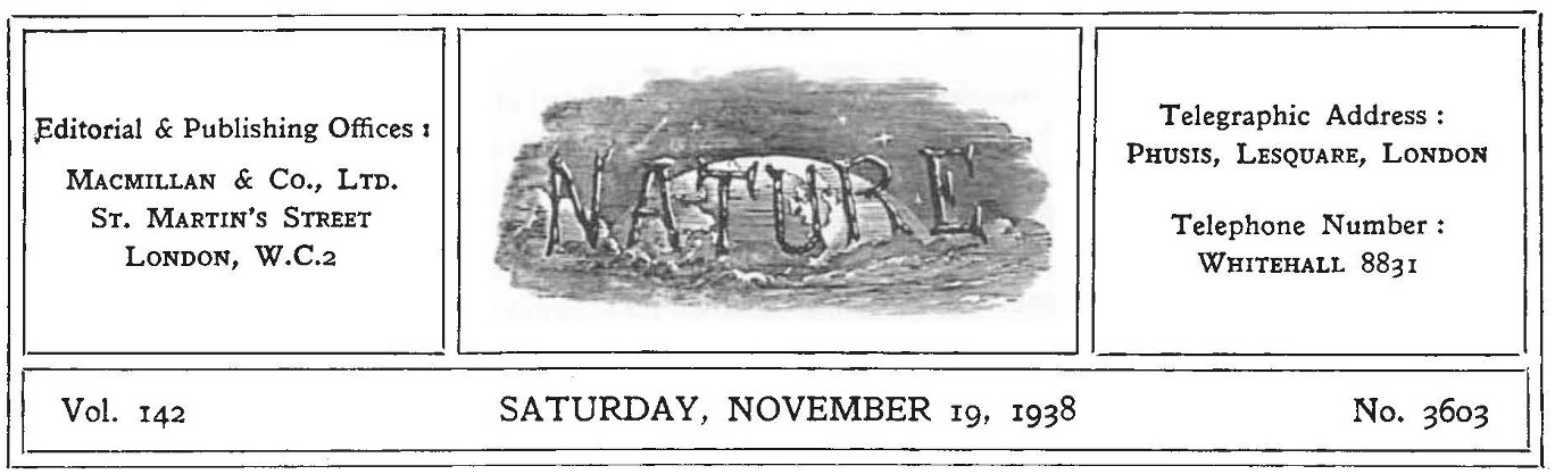

\title{
The State and Medical Research
}

$\mathrm{I}^{\mathrm{N}}$ the Harveian Oration, delivered by Sir Edward Mellanby before the Royal College of Physicians on October 18, and summarized in NATURE of October 29, certain points were raised of such importance, particularly at the present time, that it seems desirable to underline and amplify them.

A realization of the urgent need for medical research makes no call on the imagination, and demands no special medical knowledge. We have all seen pain, disease and death at close enough quarters to wish that we were better armed against them; and it is evident that the only effective arms we can hope for are those fashioned for us by science.

What is not so fully realized, at least by the general public, is that the case for extended research is stronger than ever before, because the prospects are brighter. As always in the growth of science, each new discovery brings other discoveries a little nearer, so that the potential rate of advance continuously increases. It would not have been easy, fifty years ago, to indicate how large sums of money could best be spent to hasten our acquirement of the knowledge that alone will enable us to control disease. It is certainly true to-day that our rate of advance is mainly determined by finance. We can spend, to advantage, more than there is any likelihood of our obtaining ; and the date at which mankind will be freed from the dread of such killing or disabling diseases as cancer, tuberculosis and rheumatism depends, in the main, on how much we are prepared to pay. This does not mean that a frontal attack is necessarily the best or the speediest method of gaining the knowledge that we require. The sure road to success is to stimulate the growth and development of the medical sciences as a whole. Lister followed Pasteur; aseptic surgery was the outcome of studies on fermentation. We cannot tell where we shall find the key to any of the more obstinate puzzle-locks of medicine.

It is only by adequate and wise endowment that such a growth of the medical sciences can be secured. The return such endowment would give us may reasonably be assessed in the light of our gains in the past. To take only recent advances, diabetes and pernicious anæmia, incurable and fatal diseases not many years ago, are now readily controllable. We can, if we choose, eliminate diphtheria as an important infection of childhood. We are at last in sight of an effective attack on influenza, one of the major killing diseases of adult life. The discovery of the therapeutic action of sulphanilamide, and its related compounds, has not only given us our first effective weapon against puerperal septicæmia, the main cause of maternal mortality, but also has brought bacterial infections in general into the field of chemotherapy, which hitherto seemed to be limited to protozoal diseases.

The funds required to maintain a healthy activity throughout the whole research field involved, and to concentrate additional resources at any point which promises a rapid advance, are large-large at least in terms of the inadequate resources that have been available in the past, though trivial in comparison with the sums expended on health administration that is often ineffective because it lacks the necessary knowledge on which to act. Some part of the money required may be provided by the munificence of private donors, or by public subscription. Sir Edward. 
Mellanby instanced some of the funds available for this purpose, such as those administered by the Leverhulme Trustees, the Halley Stewart Trustees, and the British Empire Cancer Campaign. There is an expectation of additional support from the Wellcome Trustees; and British medical research already owes much to the generosity of the Rockefeller Foundation of America-a generosity which, as Sir Edward emphasized, might well prick the conscience of some of our own countrymen. It is reasonable to expect more help from industry in the future than we have received in the past, particularly in the rapidly expanding field of chemotherapy ; and it is perhaps not too much to hope that our large life insurance companies, which benefit directly from the increased expectation of life consequent on the increase of medical knowledge, may one day bo stimulated by the admirable example set by similar bodies in the United States. But, whatever help is available from such sources as these, it is inevitable that the greater part of the burden should be carried by the State, for the State bears the ultimate responsibility for national health and for financing the measures that are necessary to secure it. It is in relation to the form in which State endowment can best be supplied and utilized that Sir Edward Mellanby's account of the working of the Medical Research Council is of particular interest.

Bureaucracy, giving the term its common and well-justified implication, is the inveterate enemy of research. State endowment means State control ; and if 'State' and 'bureaucratic' were synonymous terms the outlook would be dark. But the Medical Research Council, under the wise guidance of its two secretaries, the late Sir Walter Fletcher and row Sir Edward Mellanby, has shown that bureaucracy is a malignant growth that a Government department can quite easily prevent by a simple willingness to delegate, not final authority, but provisional decisions, and the carrying out of plans that have been approved. Incidentally, the Council has also shown that bureaucracy is as expensive as it is obstructive, and that its elimination leads to a great saving of public funds. Working through a large number of unpaid expert committees, the Council has encouraged those who know how research can best be stimulated and assessed to do these things for nothing. As a result, the Council's administrative expenses are a very small fraction of the total funds at its disposal, and the greater part of its financial resources are expended on the salaries of research workers, or on the laboratory expenses associated with their work.

Moreover, by enlisting the voluntary help of a large number of senior workers in universities, research institutes and hospitals, the Council has been able to co-ordinate investigations in a way which no other body could approach, and to ensure, so far as is humanly possible, that economy is safe-guarded by terminating lines of research that have served their purpose, or have failed to fulfil their promise, and by concentrating the available resources in the most promising fields. Its ability to do this, it should be noted, is largely due to the fact that it acts on the advice of those who know what is actually happening, and, as a result, has won their trust and willing co-operation. It does not seem impossible that a method which has proved so successful in one branch of Government activity might be equally effective in others. We are an empirical people, and learn more readily from experience than from argument.

One other point that was stressed by Sir Edward Mellanby deserves further amplification-the unnecessary lag that is apt to occur between the discovery of a method that is applicable to the diagnosis, cure or prevention of human disease and its adequate practical exploitation. This lag is far less conspicuous on the curative than on the preventive side. A new therapeutic agent tends to be tried out at once, and on a wide scale. The trouble is that the trial is often uncritical and uncontrolled, and that the factors that determine the use, or abuse, of the new remedy take longer than they need to win general recognition. The Medical Research Council has made a start towards removing this defect by setting up a Therapeutic Trials Committee.

It is on the preventive side, and particularly in relation to the application of new methods of preventing infective disease, that the lag is longest, and the position in Great Britain is most discreditable, perhaps because this field of activity, on its applied side, has not hitherto been regarded as falling within the Council's sphere. It is not flattering to our sense, humanity or self-respect that we have no central or regional institutes of hygiene, or State laboratories, comparable to those that have been established in the great majority of other civilized countries. The United States, in addition to the National Institute of Health at Washington, has numerous State institutes such as the Division of Laboratories and Research of the New York State Department of Health. Germany 
has the Reichsgesundheitsamte in Berlin; Denmark, the State Serum Institute in Copenhagen; Italy, the Institute of Public Health in Rome; Poland, the Institute of Hygiene at Warsaw; Hungary, the Institute of Hygiene at Budapest ; Turkey, at Ankara; Czechoslovakia, at Prague; Rumania, at Bucharest, Jassy and Cluz; Yugoslavia, at Belgrade and Zagreb; and so on.

All these institutes, though varying in their detailed functions, and in their exact relation to the State, serve as national or provincial centres which stimulate the scientific attack on infective disease, aid in the practical application of new discoveries to preventive problems, and provide, for public health administrators, facilities that they could obtain in no other way.

Other parts of the British Commonwealth are, in this matter, well ahead of Great Britain, as is shown, for example, by the admirable work carried out by the Connaught Laboratories in Toronto. Our neglect of this obvious deficiency is humiliating, and not without its dangers to health even in ordinary times. In times of emergency it may, unless remedied, entail improvisations that, with all their attendant difficulties and disadvantages, would be unnecessary if our peace-time organization were less defective.

In many ways the practice of medicine in Great Britain is as good as anywhere in the world.
British public health legislation and practice have a proud history since the days of Chadwick and Simon. Our universities and our institutes of medical research have made outstanding contributions to knowledge, and are fully capable of adding to them. Our future position in the world of medical science which, in addition to its national importance, plays no small part in international relationships and co-operation, will depend mainly on the willingness of the Government to provide the necessary funds, and on the extension to wider fields of the wise methods by which the Medical Research Council has encouraged integration, while allowing freedom and initiative, within the territory it has covered in the past. In particular, there must be a clearer recognition of the interdependence of research and practice. A problem in the prevention or cure of disease has not been solved until a finding reached in the laboratory has been tested and applied in the ward, or in the field, and has been exploited to the limits of its usefulness. The method of approach that will succeed in the earlier stages will succeed in the later, and other methods will fail. The bureaucratic method is as incapable of applying discoveries effectively as it is of making them. State endowment and encouragement of those who alone can do the work required will yield the results we need, and yield them at the minimum cost.

\section{Modern Methods in School Science}

\section{A Modern Introduction to Science}

By Dr. W. P. D. Wightman and A. O. Chesters. Part 1. Pp. vii $+158+4$ plates. 2s. $3 d$. Part 2 . Pp. vii $+170+4$ plates. 2s. 6d. Part 3. Pp. vii + $248+4$ plates. $3 s .6 d$. Part 4. Pp. viii $+275+6$ plates. $3 s .9 d$. (Edinburgh and London: Oliver and Boyd, 1936-1938.)

THERE is something arresting in the title 1 which Dr. Wightman and Mr. Chesters, of the Edinburgh Academy, have given to this series of books. "An Introduction to Modern Science" might mean many things, but "A Modern Introduction to Science" suggests that the authors have a new method of approach; and so, in fact, they have. They have shared the dissatisfaction of many teachers with the traditional ways of teaching elementary science, and their main aim is to guide a young reader towards "reasoned answers to questions to which his own curiosity naturally leads him". Accordingly, each topic is presented as a problem to be attacked in a spirit of discovery and "not as a verification of something already known". In elucidating problems, the authors often follow historical lines and usually they have done so with admirable discretion. In general, it may be said that they present science as a matter of personal concern to the young students, who are enabled to pluck the fruits of knowledge from all the main branches of the subject.

The first two parts of the series were already printed before the Science Masters' Association made its interim report (1936) on "The Teaching of General Science". In their preface to the last two parts of their work, the authors comment upon the close agreement between the findings in the report and "the principles which they had quite independently come to regard as basic". The similarity is indeed quite remarkable; for the 